Extragonadal germ cell tumors are an uncommon clinical entity. Their prevalence varies between 1 and $5 \%$ of all germ cell tumors. Approximately $85-90 \%$ of cases have metastatic changes at the time of diagnosis. In our article we would like to present a case of an 18-year-old patient who was admitted to the hospital due to acute abdominal symptoms. A day earlier, the patient suffered blunt abdominal trauma during workout. Posttraumatic changes, which were described after admission in computed tomography, intraoperatively proved to be masses of extraperitoneal tumor.

Key words: acute abdomen, mixed germ cell tumor, retroperitoneum.

\section{Isolated retroperitoneal mixed germ cell tumor presenting as acute abdomen - case report}

\author{
Piotr Misiak, Łukasz Piskorz, Sławomir Jabłoński, Jacek Mikosiński, \\ Marian Brocki, Szymon Wcisło
}

Department of Thoracic Surgery, General and Oncological Surgery University Hospital No. 2, Medical University of Lodz, Poland

\section{Introduction}

Extragonadal germ cell tumors are uncommon neoplasms which account for only $1-5 \%$. The widely accepted theory suggests that these tumors arise from primordial germ cells misplaced during their migration to the gonads [1-6]. The only documented predisposing factor is Klinefelter syndrome [3]. Extragonadal germ cell tumors are more common in children under 15 years old and primarily men between the second and fourth decade of life. The majority of extragonadal germ cell tumors occur in men, except benign mature teratoma, which occurs with equal frequency in men and women (in adults, they are found in approximately $2.7 \%$ to $7 \%$ in pure form but in $50 \%$ of mixed germ cell tumors) [5, 7].

The radiological findings of extragonadal germ cell tumors are often nonspecific, and tissue diagnosis is almost always needed to establish the final diagnosis, but they are usually situated in the median line. In adults the most common sites of localization are the mediastinum, retroperitoneum, and pineal and suprasellar regions $[3,4,6]$. Their clinical presentation depends directly on the mass and location of the primary tumor (the effect of oppression surrounding organs), and the presence of distant metastases in the case of a cell containing a lower degree of differentiation [6,7]. The way of treatment of extragonadal germ cell tumors of adolescents and adults is chemotherapy. However, over half of germ cell tumors consist of more than one cell type, requiring appropriate surgical sampling before administration of targeted chemotherapy.

\section{Case report}

An 18-year-old patient was admitted to the hospital due to severe abdominal pain. The medical interview revealed that the day before admission, the patient suffered blunt abdominal trauma during workout. Pain, which was located mainly in the epigastric region, was accompanied by nausea, vomiting and stoppage of bowel movements. The physical examination revealed severe flatulence coexisting with marked peritoneal signs. Pre-operative investigations showed WBC $19.3 \times 10^{3} / \mu \mathrm{l}(4.0-11.0)$ with increased total neutrophil count of $16.27 \times 10^{3}(2.20-4.80)$ and total bilirubin level $25.5 \mu \mathrm{mol} / \mathrm{l}(5.0-21.0)$. There were no other abnormalities. Because of the severe general condition of the patient, we decided to perform an abdominal CT scan, which revealed the presence of a non-homogeneous area of size $8.2 \times 8.5 \times 5 \mathrm{~cm}$ extending between the pancreas, transverse colon, the right lobe of the liver, aorta and vena cava. The lesion was initially described as hematoma, which caused oppression of adjacent organs. In addition, a description of the CT suggested the possibility of damage to the anterior wall of the inferior vena cava at a length of about $2 \mathrm{~cm}$ below the mouth of the renal vein. After administration of contrast, radiology test suggested that there were some features indicating the possibility of continuous bleeding. Moreover, near the descending colon there were 


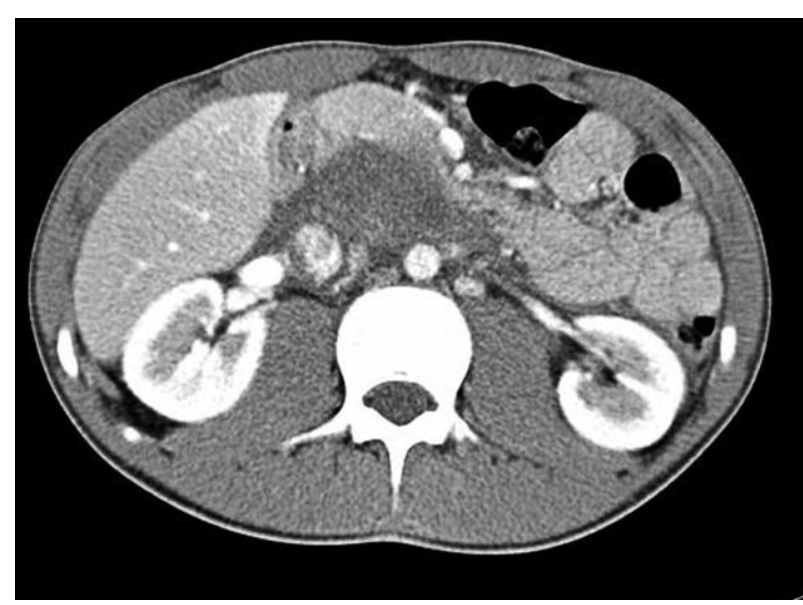

Fig. 1. Abdomen CT scan. Day of admission

some features indicating free air in the abdominal cavity, the CT image indicating the possibility of post-traumatic rupture of the intestine (Fig. 1). Therefore there was no more time for additional examinations and the patient was qualified for urgent laparotomy. To our great surprise, intraoperatively we found an enormous, disintegrating retroperitoneal tumor. The tumor infiltrated the wall of the aorta and vena cava. We performed a cytoreductive procedure. The biological material was sent for pathological examination. On the first day after the operation we assessed serum tumor markers which revealed LDH (lactate dehydrogenase) $344 \mathrm{U} / \mathrm{l}$ (80-240 U/l), AFP ( $\alpha$-fetoprotein) $12270 \mathrm{ng} / \mathrm{ml}$ (< $8 \mathrm{ng} / \mathrm{ml})$. $\beta$-hCG ( $\beta$-human chorionic gonadotropin) and CEA (carcinoembryonic antigen) were within normal limits. We did not detect any focal lesions in testicular ultrasound examination. The final pathological examination was established after one week (mixed germ cell tumor: embryonal carcinoma and yolk sac tumor).

After ten days of hospitalization the patient was transferred to a regional oncology center for further treatment.

The patient is still alive (two years after the first operation). So far the patient has undergone twelve cycles of chemotherapy, initially according to the TGM 95 program. During these two years of treatment the patient was qual-

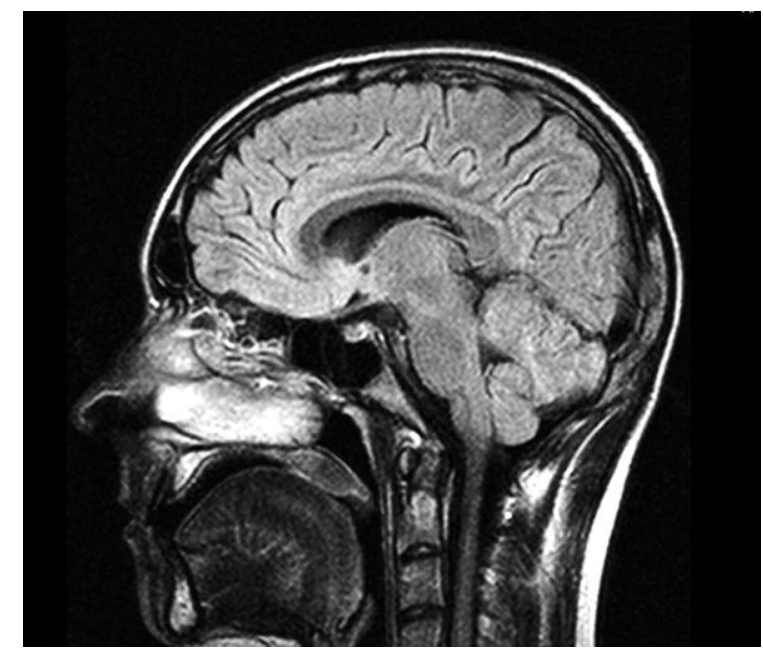

Fig. 3. Brain MRI. No distant metastases

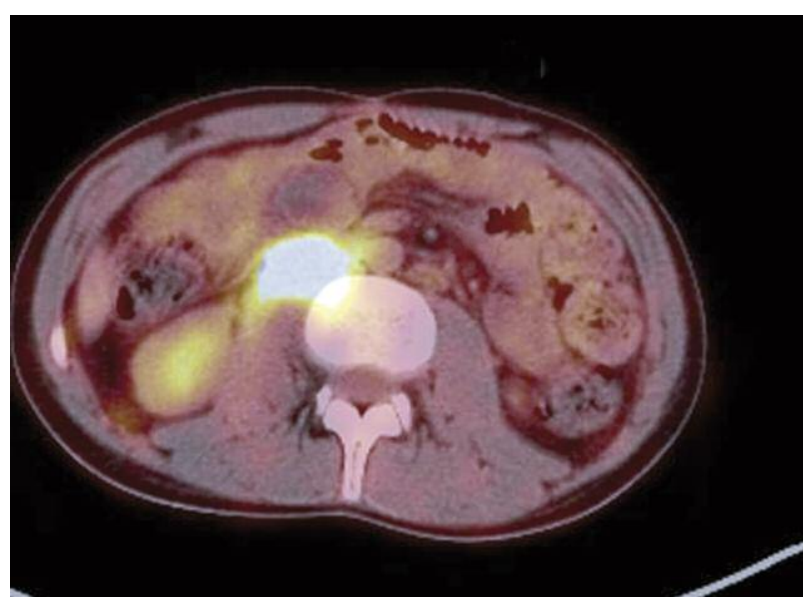

Fig. 2. Local recurrence in lumbar region

ified for two operations: the first operation was cytoreductive R2 (histopathological examination revealed tumor cells in surrounding tissues), and the second one was radical (tumor resection with anterior wall of vena cava). Despite the complex and multi-stage treatment the PET-CT examination performed in January 2012 revealed a local recurrence of the tumor (Fig. 2).

\section{Discussion}

Extragonadal mixed germ cell tumors most frequently occur in the anterior mediastinum (60\%) and approximately $30 \%$ occur in extraperitoneal localization. Extragonadal germ cell tumors are considered metastases from occult or "burned out" gonadal cancer until proved otherwise. Primary isolated extraperitoneal mixed germ cell tumors constitute approximately $10 \%$ of all primary malignant retroperitoneal tumors [3]. Histologically, extragonadal germ cell tumors comprise seminomas (30-40\%), nonseminomatous tumors (60-70\%) in men and dysgerminomas and non-dysgerminomas in women. The majority of these tumors occur in men, mostly in two age brackets: under 15 years of age and between the second and fourth decade of life. Sixty percent of tumors in adults contain mixed cells $[3,4]$.

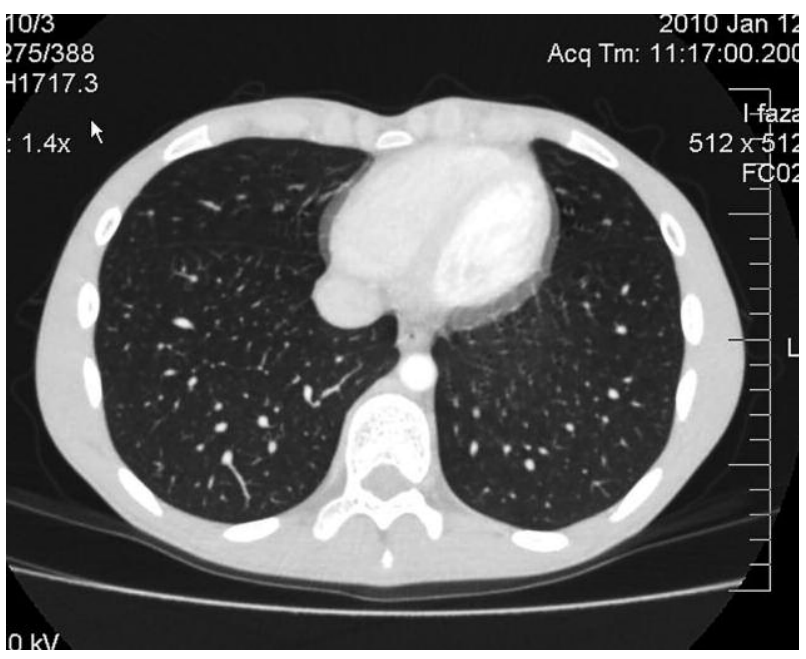

Fig. 4. Chest CT. No distant metastases 
Metastases occur in $61 \%$ of adults and only $9 \%$ of children [4].

The imaging examinations such as CT scans do not indicate clear features that distinguish germ tumors from lymphomas, sarcomas or metastatic tumors; the one fairly characteristic feature for extragonadal mixed germ cell tumors is their location in the midline of the body [3-7].

Tumor markers are usually helpful in the diagnosis and follow-up of extragonadal germ cell tumors. $\beta$-hCG is elevated in embryonal carcinoma, choriocarcinoma and in approximately $10 \%$ of cases of seminomas. $\alpha$-Fetoprotein is elevated in embryonal carcinoma and endodermal sinus tumors (yolk sac tumor) $[3,6,7]$.

In the above-described case there was no time to do such additional testing before surgery. The main indication for urgent laparotomy was the severe clinical condition of the patient and CT examination which indicated the possibility of rupture of the inferior vena cava and intestine.

Over half of germ cell tumors consist of more than one cell type, requiring appropriate sampling for the correct diagnosis and further treatment. Moreover, these tumors may give rise to secondary malignancies; especially residual tumor may occur in approximately $10 \%$ of somatic type malignancies, e.g., adenocarcinoma or rhabdomyosarcoma $[6,7]$. This is one of the reasons why cisplatin-based chemotherapy is not always effective against extragonadal germ cell tumors [6, 7]. In spite of the success of chemotherapy in the treatment of extragonadal germ cell tumors, about $20 \%$ of patients with metastases die as a result of their tumor [6]. So far the patient who was operated on in our clinic has no distant metastases (Fig. 3, Fig. 4); however, the latest PET-CT examination revealed local recurrence in the lumbar region (Fig. 2).

\section{References}

1. Abe H, Tani T, Naitoh H, Kodama M. Retroperitoneal germ cell tumor treated by PVeBV chemotherapy: a case report. Jpn J Clin Oncol 1999; 29: 261-3.

2. Womeldorph CM, Zalupski MM, Knoepp SM, Soltani M, Elmunzer BJ. Retroperitoneal germ cell tumor diagnosed by endoscopic ultrasound-guided fine needle aspiration. World I Gastrointest Oncol 2010; 2: 443-5.

3. Shinagare AB, Jagannathan JP, Ramaiya NH, Hall MN, Van den Abbeele AD. Adult extragonadal germ cell tumors. AJR Am J Roentgenol 2010; 195: 274-280.

4. Bujons A, Caffaratti J, Pascual M, Angerri O, Garat JM, Villavicencio H. Testicular tumours in infancy and children. Actas Urol Esp 2011; 35: 93-8.

5. Weidner N. Germ-cell tumors of the mediastinum. Semin Diagn Pathol 1999; 16: 42-50.

6. Looijenga LH, Oosterhuis JW. Pathogenesis of testicular germ cell tumours. Rev Reprod 1999; 4: 90-100.

7. Sesterhenn IA, Davis CJ Jr. Pathology of germ cell tumors of the testis. Cancer Control 2004; 11: 374-87.

\section{Address for correspondence}

Piotr Misiak MD, PhD

ul. Długa 35, Chechło

95-082 Dobroń

e-mail: pitmis@interia.pl

Submitted: $\quad 11.11 .2011$

Accepted: $\quad$ 19.03.2012 